\title{
Current Challenges and Concepts of the Thermomechanical Treatment of Nickel-Titanium Instruments
}

\author{
Ya Shen, DDS, PhD, ${ }^{*}$ Hui-min Zhou, DDS, PbD, ${ }^{\dagger}$ Yu-feng Zbeng, PhD, ${ }^{\ddagger}$ Bin Peng, DDS, PhD, ${ }^{\downarrow}$ \\ and Markus Haapasalo, DDS, $P b D^{*}$
}

\begin{abstract}
Introduction: The performance and mechanical properties of nickel-titanium (NiTi) instruments are influenced by factors such as cross-section, flute design, raw material, and manufacturing processes. Many improvements have been proposed by manufacturers during the past decade to provide clinicians with safer and more efficient instruments. Methods: The mechanical performance of NiTi alloys is sensitive to their microstructure and associated thermomechanical treatment history. Heat treatment or thermal processing is one of the most fundamental approaches toward adjusting the transition temperature in NiTi alloy, which affects the fatigue resistance of NiTi endodontic files. The newly developed NiTi instruments made from controlled memory wire, M-Wire (Dentsply Tulsa Dental Specialties, Tulsa, OK), or R-phase wire represent the next generation of NiTi alloys with improved flexibility and fatigue resistance. The advantages of NiTi files for canal cleaning and shaping are decreased canal transportation and ledging, a reduced risk of file fracture, and faster and more efficient instrumentation. The clinician must understand the nature of different NiTi raw materials and their impact on instrument performance because many new instruments are introduced on a regular basis. Results: This review summarizes the metallurgical properties of next-generation $\mathrm{NiTi}$ instruments, the impact of thermomechanical treatment on instrument flexibility, and the resistance to cyclic fatigue and torsion. Conclusions: The aim of this review was to provide clinicians with the knowledge necessary for evidence-based practices, maximizing the benefits from the selection and application of NiTi rotary instruments for root canal treatment. (J Endod 2013;39:163-172)
\end{abstract}

\section{Key Words}

Controlled memory wire, endodontic instrument, fatigue, heat treatment, M-wire, nickel-titanium, R-phase, torque

O ver the past 2 decades, nickel-titanium (NiTi) instruments have become an important part of the armamentarium for root canal treatment. They are increasingly used by generalists and specialists to facilitate the cleaning and shaping of root canals. Despite their undeniably favorable qualities, there is a potential risk of "unexpected" fracture with NiTi instruments (1-10). Even though there have been considerable improvements in the file design and manufacturing methods on endodontic rotary instruments made of NiTi alloys, rotary instrument intracanal separation caused by cyclic fatigue remains a concern, especially in root canals with severe curvatures (11-16). The mechanical behavior of NiTi alloy is determined by the relative proportions and characteristics of the microstructural phases. Heat treatment (thermal processing) is one of the most fundamental approaches toward adjusting the transition temperatures of NiTi alloys (17-19) and affecting the fatigue resistance of NiTi endodontic files. In recent years, several novel thermomechanical processing and manufacturing technologies have been developed to optimize the microstructure of NiTi alloys. As more thermomechanically processed endodontic NiTi files such as HyFlex CM (HyFlex; Coltene Whaledent, Cuyahoga Falls, OH), K3XF (SybronEndo, Orange, CA), ProFile GT Series X (GTX; Dentsply Tulsa Dental Specialties, Tulsa, OK), ProFile Vortex (Vortex) and Vortex Blue (Dentsply Tulsa Dental Specialties), Reciproc (VDW, Munich, Germany), TYPHOON Infinite Flex NiTi (TYP CM; Clinician's Choice Dental Products, New Milford, CT), Twisted Files (TFs; SybronEndo, Orange, CA), and WaveOne (Dentsply Maillefer, Ballaigues, Switzerland) are introduced, understanding the nature of different raw materials and their impact on instrument performance has become even more imperative than before for clinicians as it relates to choosing instrument and achieving the desired outcome.

\section{Properties of NîTi Alloy}

NiTi is called an exotic metal because it does not conform to the normal rules of metallurgy. The NiTi alloys used in root canal treatment contain approximately $56 \%$ (wt) nickel and 44\% (wt) titanium (20). The resultant combination is a 1:1 atomic ratio (equiatomic) of the major components, and, similar to other metallic systems, the alloy can exist in various crystallographic forms. Nearequiatomic NiTi alloys contain 3 microstructural phases (ie, austenite, martensite,

From the *Division of Endodontics, Department of Oral Biological and Medical Sciences, Faculty of Dentistry, The University of British Columbia, Vancouver, Canada; ${ }^{\dagger}$ Center for Biomedical Materials and Engineering, College of Material Science and Chemical Engineering, Harbin Engineering University, Harbin, China; ${ }^{\ddagger}$ State Key Laboratory for Turbulence and Complex Systems and Department of Materials Science and Engineering, College of Engineering, Peking University, Beijing, China; and ${ }^{\S}$ State Key Laboratory Breeding Base of Basic Science of Stomatology (Hubei-MOST) and Key Laboratory of Oral Biomedicine Ministry of Education, School and Hospital of Stomatology, Wuhan University, Wuhan, China.

Address requests for reprints to Dr Markus Haapasalo, Division of Endodontics, Department of Oral Biological and Medical Sciences, UBC Faculty of Dentistry, 2199 Wesbrook Mall, Vancouver, BC, Canada V6T 1Z3. E-mail address: markush@dentistry.ubc.ca

0099-2399/\$ - see front matter

Copyright () 2013 American Association of Endodontists.

http://dx.doi.org/10.1016/j.joen.2012.11.005 
and R-phase), the character and relative proportions of which determine the mechanical properties of the metal (21). NiTi alloy has special characteristics of superelasticity and shape memory. Because it is a superelastic (SE) metal, the application of stress does not result in the usual proportional strain seen in stainless steel. The superelasticity of NiTi allows deformations of as much as $8 \%$ strain to be recoverable in comparison with a maximum of less than $1 \%$ with stainless steel. This unusual property is the result of stressinduced martensite transformation. External stresses transform the austenitic crystalline form of NiTi into a martensitic crystalline structure that can accommodate greater stress without increasing the strain. As a result of its unique crystalline structure, a NiTi file has superelasticity (ie, the ability to return to its original shape after being deformed). Simply stated, NiTi alloys currently are the only readily available and affordable materials with the flexibility and toughness for routine use as effective rotary endodontic files in curved canals. Superelasticity occurs in association with a reversible phase transformation between austenite and martensite. Therefore, the transformation temperatures have a critical influence on the mechanical properties and the behavior of NiTi, which can be altered by small changes in composition, impurities, and heat treatments during the manufacturing process (22). This distinct property of NiTi alloys has created a revolution in the manufacture of endodontic instruments.

The NiTi shape memory alloy can exist in 2 different temperaturedependent crystal structures (phases) called martensite (low-temperature phase, with a monoclinic B19' structure) and austenite (high temperature or parent phase, with the B2 cubic crystal structure). Several properties of austenite NiTi and martensite NiTi are notably different $(23,24)$. When martensite NiTi is heated, it begins to change into austenite. The temperature at which this phenomenon begins is called the austenite transformation start temperature $\left(A_{s}\right)$. The temperature at which this phenomenon is complete is called the austenite finish temperature $\left(\mathrm{A}_{\mathrm{f}}\right)$, which means that at and above this temperature the material will have completed its shape memory transformation and will display its SE characteristics. When austenite NiTi is cooled, it begins to change into martensite. The temperature at which this phenomenon begins is called the martensite transformation start temperature $\left(\mathrm{M}_{\mathrm{S}}\right)$. The temperature at which martensite is again completely reverted is called the martensite transformation finish temperature $\left(\mathrm{M}_{\mathrm{f}}\right)(23,24)$. The $\mathrm{A}_{\mathrm{f}}$ temperature for most conventional SE NiTi files is at or below room temperature, whereas the $A_{f}$ of the new controlled memory (CM) files (TYP) is clearly above body temperature. As a result, the conventional NiTi files are in the austenite phase during clinical use, whereas CM files are mainly in the martensite phase (25).

Composition and metallurgical treatments have dramatic impacts on these transition temperatures. From the point of view of practical applications, NiTi can have 3 different forms: martensite, stress-induced martensite (SE), and austenite. When the material is in its martensite form, it is soft and ductile and can easily be deformed. SE NiTi is highly elastic, whereas austenitic NiTi is quite strong and hard (25). The equiatomic NiTi alloy has all these properties, with the specific expression being dependent on the temperature at which it is used.

Brantley et al (26) were the first ones in the endodontic literature to show that the structure of the NiTi rotary instruments can be conveniently investigated by differential scanning calorimetry (DSC). They indicated that the $\mathrm{A}_{\mathrm{f}}$ temperature of conventional NiTi rotary instruments (Lightspeed and ProFile) was near $25^{\circ} \mathrm{C}$ at room temperature. Therefore, these instruments would show SE behavior during clinical use.

\section{Metallurgical Characterization of Thermomechanically-treated Nîii Instruments}

At the beginning of 2000, a series of studies (27-30) found that changes in the transformation behavior via heat treatment were effective in increasing the flexibility of NiTi endodontic instruments. Since then, heat-induced or heat-altering manipulations were used to influence or alter the properties of NiTi endodontic instruments, which were once cited as the main reasons for pursuing the use of NiTi instruments in endodontics. Proprietary thermomechanical processing is a complicated process that integrates hardening and heat treatment into a single process. Alapati et al (31) found that heat treatments at $400^{\circ} \mathrm{C}, 500^{\circ} \mathrm{C}$, and $600^{\circ} \mathrm{C}$ raised the $\mathrm{A}_{\mathrm{f}}$ temperature of ProFile to $45^{\circ} \mathrm{C}-50^{\circ} \mathrm{C}$, and heat treatment at $850^{\circ} \mathrm{C}$ caused a loss of SE behavior and recrystallization of the wrought microstructure. DSC curves were very complex with irregular peaks. These results were also confirmed by other studies $(28,32)$. Therefore, the manufacturer must perform an appropriate heat treatment, which will be accompanied by beneficial changes in mechanical properties and improved clinical performance.

Recently, a different approach has been used to optimize the structure of the NiTi wire blanks for rotary instruments. A series of proprietary thermomechanical processing procedures has been developed with the objective of producing SE NiTi wire blanks that contain the substantially stable martensite phase under clinical conditions. Enhancements in these areas of material management have led to the development of the next-generation endodontic instruments.

M-Wire (Dentsply Tulsa Dental Specialties) was introduced in 2007 and is produced by applying a series of heat treatments to NiTi wire blanks. M-Wire instruments include Dentsply's ProFile GT Series $\mathrm{X}$, ProFile Vortex, and Vortex Blue. In 2008, a new manufacturing process was also developed by SybronEndo to create a NiTi endodontic instrument-TFs. According to the manufacturer, TF instruments were developed by transforming a raw NiTi wire in the austenite phase into the R-phase through a thermal process (product brochure: www. tfwithrphase.com/images/3987_TF_Brochure.pdf). The R-phase is an intermediate phase with a rhombohedral structure that can form during forward transformation from martensite to austenite on heating and reverse transformation from austenite to martensite on cooling. It occurs within a very narrow temperature range.

CM Wire (DS Dental, Johnson City, TN) is a novel NiTi alloy with flexible properties that was introduced in 2010. CM NiTi files have been manufactured using a special thermomechanical process that controls the memory of the material, making the files extremely flexible but without the shape memory of other NiTi files, as opposed to what is found with conventional SE forms of NiTi (product brochure: http://www.hyflexcm.com/DevDownloads/30464A_HYFLEX-CM_bro.pdf) (33). Both HyFlex and TYP are made from CM Wire.

The martensitic phase of NiTi has some unique properties that have made it an ideal material for many applications (34). The martensitic form of NiTi has remarkable fatigue resistance. Instruments in the martensite phase can easily be deformed, yet they will recover their shape on heating above the transformation temperatures. The explanation for this may be that heating transforms the metal temporarily into the austenitic phase and makes it SE, which makes it possible for the file to regain its original shape before cooling down again. The properties of the bulk materials are the main determinant of fatigue life (35-42). CM Wire and M-Wire instruments have increased austenite transformation temperatures. The $\mathrm{A}_{\mathrm{f}}$ of $\mathrm{CM}$ Wire, M-Wire, TF, and conventional SE NiTi wire are approximately $55^{\circ} \mathrm{C}, 50^{\circ} \mathrm{C}, 17^{\circ} \mathrm{C}$, and $16^{\circ}-31^{\circ} \mathrm{C}$, respectively (42-45). The conventional SE NiTi file has an austenite structure (26, 42-46), whereas NiTi file with thermal processing (eg, TYP CM 


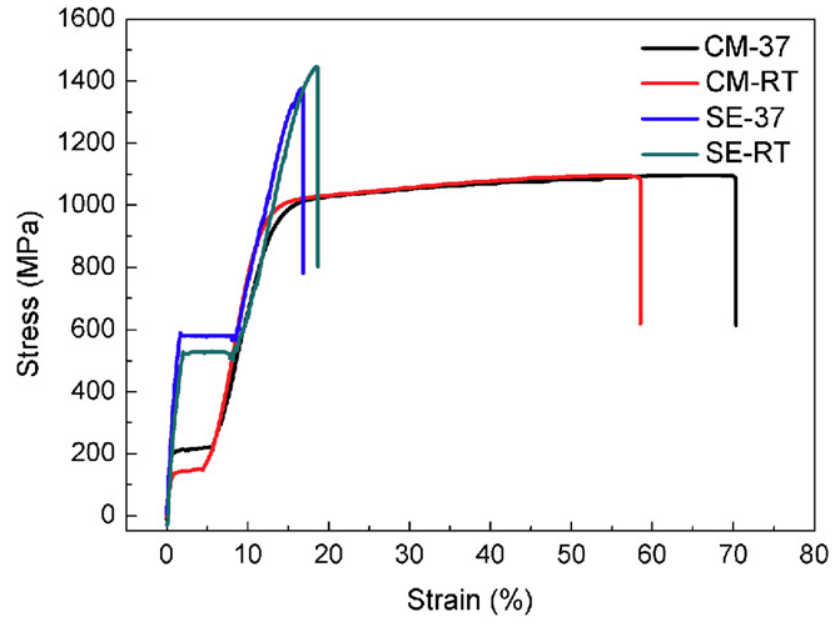

Figure 1. The tensile stress-strain curves of as-received CM and SE wires with a diameter of $0.64 \mathrm{~mm}$. The test was conducted at room temperature (RT) and oral temperature $\left(37^{\circ} \mathrm{C}\right)$.

and Vortex) would essentially be in the martensite condition at body temperature $(42,44,45,47)$. In addition, the critical stress for martensite reorientation of CM Wires is in the range of 128-251 MPa at room temperature and $37^{\circ} \mathrm{C}$, which is much lower than the critical stress for stress-induced martensite transformation of the SE wires (490-582 MPa) (42). The ultimate tensile strength for the CM Wires (about $1094 \mathrm{MPa}$ ) is also lower than that of SE wires (about 1415 $\mathrm{MPa}$. However, the maximum strain of $\mathrm{CM}$ Wires before fracture $(58.4 \%-84.7 \%)$ is much higher than that of the SE wires $(16.7 \%-27.5 \%)$ (Fig. 1). These results indicate the superior flexibility of CM Wire compared with conventional SE NiTi wire.

The superelasticity of the NiTi alloy means that it cannot maintain a spiral shape as the alloy undergoes nonpermanent deformation; therefore, a grinding technique was initially used in the manufacture of SE NiTi instruments. Contrary to this, TF is a recently introduced NiTi rotary file manufactured with a twisting method. It is fabricated by transforming austenite NiTi wire into the R-phase through a thermal process. Once the R-phase is identified, wire in this state can be twisted. After additional thermal procedures to maintain its new shape, the instrument is converted back into the austenite phase, which is SE once stressed. This proprietary technology was used to optimize the phase constituents and properties of TF NiTi files (48). The 2-step transformation through an apparent R-phase can be observed for TFs in DSC curves $(43,44)$

\section{Mechanical Performance of Thermomechanically-treated NiTi Instruments}

Two mechanisms that may lead to NiTi rotary fracture, namely cyclic fatigue and torsional overloading, have been described $(2,13$, 49-51). Cyclic fatigue occurs as a result of rotation around a curve by repeated extension and compression of the metal and, finally, work hardening followed by fracture $(15,49)$. Torsional fracture occurs when the tip of the rotating instrument binds in the canal while the motor continues to rotate $(2,13)$. Torsional fracture of the material occurs when the ultimate strength of the material is exceeded. Thus, an instrument needs to be resistant to cyclic fatigue and have sufficient flexibility to permit the preparation of curved systems but also sufficient torque strength so that instrument separation does not occur. Fatigue has been implicated as the main reason for the fracture of endodontic rotary files used clinically $(11,14)$.

\section{Fatigue Properties}

For NiTi alloys, the total fatigue life consists of 3 stages: (1) crack initiation, in which microcracks form and start to grow preferentially along specific crystallographic planes or grain boundaries followed by (2) crack propagation, in which the crack grows continuously, until (3) the crack reaches the point where the remaining material is overstressed and the result is the overload zone results. The overload zone features a typical dimple rupture or so-called ductile failure $(35,50,52)$. A hybrid (austenite-to-martensite) microstructure with a certain proportion of martensite is more likely to have favorable fatigue resistance than a fully austenitic microstructure (53). This is generally explained by the fatigue-crack growth resistance of the martensite, which is found to be superior to that of stable austenite, particularly near the threshold, by comparing the fatigue behavior of the various microstructures in nitinol (53). At the same stress intensity level, the fatigue crack propagation speed of austenitic structures is much faster than that of martensite ones. In addition, the martensitic phase transformation has excellent damping characteristics because of the energy absorption characteristics of its twinned phase structure. Although TFs consist mainly of austenite in the oral environment, the bending load values in elastic and SE ranges were lower for TFs than those of conventional SE NiTi files (43). Therefore, the manufacturers claim that the thermomechanical treatment of NiTi instruments yields greater resistance to cyclic fatigue when compared with conventional SE NiTi instruments.

To date, there is no specification or international standard to test the cyclic fatigue resistance of endodontic rotary instruments. Four methods (13) have been used to investigate in vitro fatigue fracture resistance of NiTi rotary endodontic instruments: (1) curved metal tube (49), (2) grooved block-and-rod assembly (54-60), (3) rotation against an inclined plane $(61,62)$, and (4) 3-point bend of a rotating instrument (32, 63, 64). However, in an effort to understand the nature of the metal alterations and their impact on enhancing resistance to fatigue in particular, an international standard for cyclic fatigue testing of NiTi rotary instruments should be developed in order to ensure the uniformity of methodologies so that the resulting data can be compared (15).

\section{Wire}

Instruments made from CM Wire (TYP CM and DSSS0250425NEYY CM [NEYY CM]) were nearly 300\%-800\% more resistant to fatigue failure than instruments made from conventional NiTi wire with the same design in a dry condition in a 3-point bending device (39) (Table 1). The square (NEYY CM) configuration of NiTi instruments made from CM Wire showed a significantly longer fatigue life than the triangular configuration (TYP CM). Therefore, the design of the instrument should also be taken into account because it is an important determinant of the fatigue lifetime. Fractographically, a single-crack origin is usually found in conventional NiTi wire files. CM Wire instruments had a higher number of multiple-crack origins than conventional NiTi wire files of the same design, especially NEYY CM instruments $(92 \%$ files with multiple-crack origins). Nearly all of the specimens showed fatigue crack initiation at 1 or more cutting edges of the fracture crosssection unless a subsurface void or inclusion was present elsewhere (39). The values of the fracture area occupied by the dimple region (showing the final fracture) were significantly smaller on NiTi instruments made from CM Wire than on instruments made from 
TABLE 1. A List of Literature on the Mechanical Properties of Thermomechanically Treated NiTi Instruments with Continuous Rotation

\begin{tabular}{|c|c|c|c|c|}
\hline & Phase transformation & Flexible property & Cyclic fatigue & Torsional fracture \\
\hline $\begin{array}{l}\text { CM Wire (HyFlex } \\
\text { CM, TYPHOON } \\
\text { Infinite Flex NiTi) }\end{array}$ & Shen et al, 2011 (44) & $\begin{array}{l}\text { Testarelli et al, } 2011 \text { (105); } \\
\text { Zhou et al, } 2012 \text { (42) }\end{array}$ & $\begin{array}{l}\text { Shen et al, } 2011(39) ; \\
\text { Shen et al, } 2012(40) ; \\
\text { Peters et al, } 2012(92)\end{array}$ & $\begin{array}{l}\text { Casper et al, } 2011(95) \text {; } \\
\text { Peters et al, } 2012(92)\end{array}$ \\
\hline $\begin{array}{l}\text { M-Wire (ProFile GT } \\
\text { Series X, ProFile } \\
\text { Vortex, Vortex } \\
\text { Blue) }\end{array}$ & $\begin{array}{l}\text { Alapati et al, } 2009 \text { (47); } \\
\text { Shen et al, } 2011(44) ; \\
\text { Ye and Gao, } 2012(45)\end{array}$ & Gao et al, 2012 (41) & $\begin{array}{l}\text { Gambarini et al, } 2008(66) ; \\
\text { Johnson et al, } 2008(68) ; \\
\text { Larsen et al, } 2009(69) ; \\
\text { Kramkowski and Bahcall, } \\
\quad 2009 \text { (90); } \\
\text { Gao et al, } 2010(38) ; \\
\text { Al-Hadlaq et al, 2010 (67); } \\
\text { Hilfer et al, } 2011(84) ; \\
\text { Gao et al, } 2012(41) ; \\
\text { Plotino et al, } 2012(86)\end{array}$ & $\begin{array}{l}\text { Johnson et al, } 2008(68) ; \\
\text { Kramkowski and Bahcall, } \\
2009(90) ; \\
\text { Casper et al, } 2011(95) ; \\
\text { Bardsley et al, } 2011(100) ; \\
\text { King et al, } 2012(96) ; \\
\text { Gao et al, } 2012(41)\end{array}$ \\
\hline $\begin{array}{l}\text { R-phase wire } \\
\text { (K3XF, TFs) }\end{array}$ & $\begin{array}{l}\text { Hou et al, } 2011(43) ; \\
\text { Shen et al, } 2011 \text { (44) }\end{array}$ & $\begin{array}{l}\text { Gambarini et al, 2008 (48); } \\
\text { Hou et al, } 2011 \text { (43) }\end{array}$ & $\begin{array}{l}\text { Gambarini et al, } 2008(66) ; \\
\text { Larsen et al, } 2009(69) ; \\
\text { Kim et al, } 2010(70) ; \\
\text { Bhagabati et al, } 2011(71) \\
\text { Rodrigues et al, } 2011(72) ; \\
\text { Pedullà et al, } 2011(73) ; \\
\text { Hilfer et al, } 2011 \text { (84) }\end{array}$ & $\begin{array}{l}\text { Gambarini et al, } 2009 \text { (98); } \\
\text { Park et al, } 2010(93) ; \\
\text { Gambarini et al, } 2010 \text { (97); } \\
\text { Casper et al, } 2011(95) ; \\
\text { King et al, } 2012(96)\end{array}$ \\
\hline
\end{tabular}

conventional NiTi wire (Fig. $2 A-D$ ). Hence, it is not surprising that CM series files had fatigue resistance superior to that of files made from conventional NiTi alloy.

Endodontic instruments are used to prepare the root canal in the presence of an irrigating solution. A recent study (40) showed that 2 CM Wire instruments (ie, TYP CM and NEYY CM) yielded a 4-9 times longer fatigue life than conventional NiTi files with the same design under various solutions. The fatigue life of 3 conventional SE NiTi instruments was unaffected by the environments, whereas the fatigue life of the 2 CM file types was much longer in liquid media than in air. This may imply that the fatigue of NiTi alloys is sensitive to temperature, both locally and environmentally. A function of the aqueous media in metal fatigue behavior is to carry the heat away from the metal-to-metal contact. Therefore, an aqueous medium seems to serve as an effective heat sink to facilitate the long fatigue life of the CM instrument.

\section{M-Wire}

A few years ago, a modification of the SE508 NiTi alloy used for endodontic instruments was developed (65) by Dentsply (M-Wire). Several studies have examined the fatigue resistance of M-Wire NiTi files (38, 41, 66-68). However, the results from these studies cannot easily be compared with one another because of variations in the experimental design and testing model.

A major drawback of most laboratory testing of the fatigue behavior of NiTi rotary instruments is the inability to eliminate several confounding factors, such as material properties, design, and
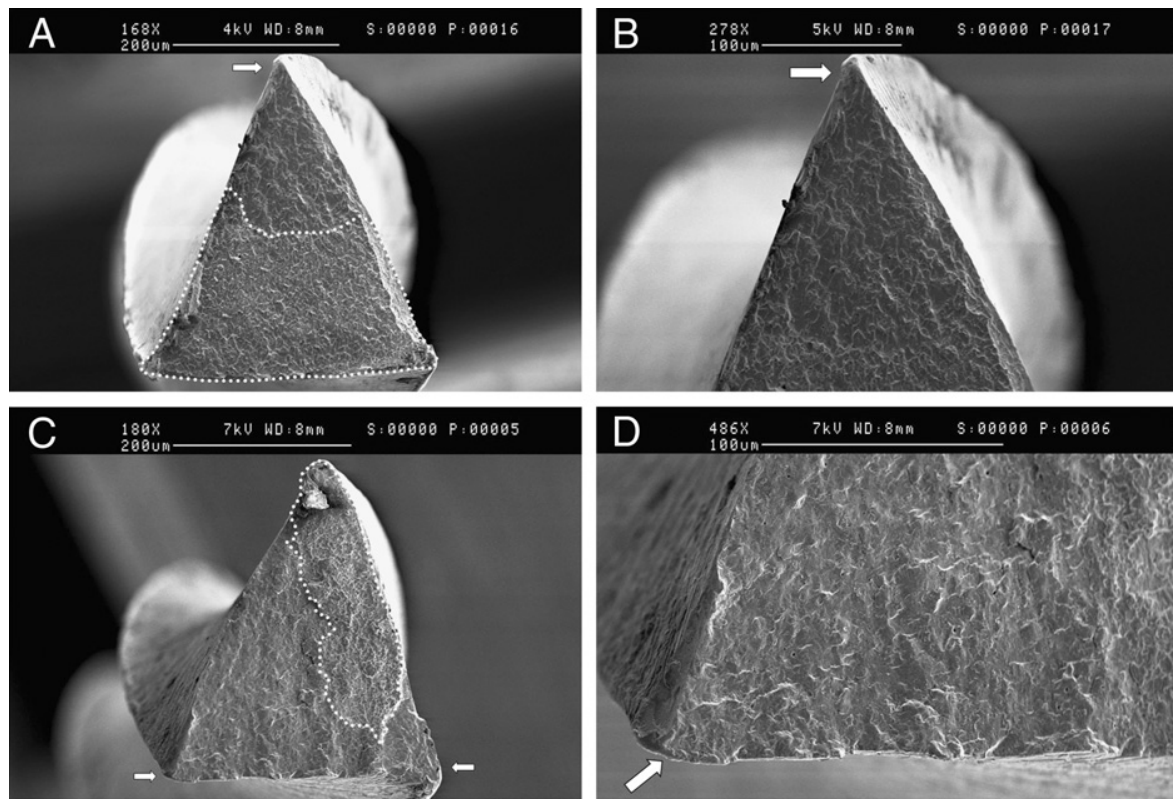

Figure 2. Photomicrographs of a fracture surface of TYP files with the region of fatigue crack propagation and dimple area outlined (dotted line) with crack origins (arrows). (A) The overall view of the TYP file $\left(\mathrm{N}_{\mathrm{f}}=315\right.$, dimple area is 69\%). (B) A high-magnification view of the crack origin $($ arrow). $(C)$ An overall view of the TYP CM file with 2 crack origins (arrows) $\left(\mathrm{N}_{\mathrm{f}}=1280\right.$, dimple area is 36\%). (D) A high-magnification view of 1 crack origin $($ arrow). 
dimensions of the instrument, which are specific to the brand(s) being tested. This has made it difficult to quantify the effect of a single variable on fatigue behavior. It is important to evaluate the influence of raw materials on the fatigue and mechanical properties by using a similar file design. Johnson et al (68) reported that instruments made from M-Wire with a ProFile design exhibited nearly $400 \%$ more resistance to cyclic fatigue than SE wire instruments of the same size. Gao et al (38) compared the cyclic fatigue resistance of ProFile Vortex rotary instruments made of 2 different raw materials: M-Wire and regular SE wire at 2 different rotational speeds. ProFile Vortex files made from M-Wire exhibited superior cyclic fatigue resistance (150\% longer fatigue life) compared with those made from regular SE wire at 2 test speeds (ie, 300 and $500 \mathrm{rpm}$ ). There was no significant difference in fatigue resistance under different rotational speeds of 300 and 500 $\mathrm{rpm}$. The fatigue life of M-Wire in this study is different from that reported by Johnson et al (68). This can partially be explained by the fact that the file design of the traditional ProFile files is considerably different from that of new ProFile Vortex files (triangular crosssection without noncutting radial land).

Recently, Gao et al (41) evaluated the impact of raw materials (including stainless steel, conventional SE NiTi, M-Wire NiTi, and Vortex Blue NiTi) on the fatigue resistance of rotary instruments $(25 / .06)$ by rotating the files in an artificially constructed stainless steel canal. Results showed that there were significant differences in the average fatigue life and flexibility for instruments made from different materials. Vortex Blue was ranked first in both fatigue life and flexibility followed by M-Wire, SE wire, and finally stainless steel.

\section{R-Phase}

The TF is a NiTi rotary file manufactured with R-phase alloy using a twisting method. It has been reported to have a higher fatigue fracture resistance than ground files $(66,69-72)$. Pedulla et al (73) evaluated the resistance to cyclic fatigue of the TF, Mtwo (VDW, Munich, Germany), and Revo S Shaping Universal (SU; Micro Mega, Besancon, France) files after immersion in sodium hypochlorite. The results showed that static or dynamic immersion in $\mathrm{NaOCl}$ for 1 or 5 minutes did not reduce the fatigue resistance (in dry condition tests) of NiTi files. The TF was more resistant followed by Mtwo and Revo S SU files. The R-phase shows good superelasticity and shape memory effects; its Young modulus is typically lower than that of austenite. Thus, an instrument made from the R-phase wire would be more flexible (36). Also, the stress hysteresis was obviously smaller for TFs than for ground files (36). A narrower stress hysteresis means that more austenite can be transformed during the stressinduced martensitic transformation (74). Hence, it is not surprising that a higher fatigue resistance was found in TFs than in conventional NiTi files.

Electropolishing is 1 method of achieving a smooth surface on NiTi instruments $(36,75-77)$. Several studies indicated that electropolishing may improve the working properties of NiTi instruments $(76,77)$, whereas Herold et al (78) showed that electropolishing did not prevent the development of microfractures. The manufacturer claims that the TF has been treated with a special surface treatment to reduce the surface irregularities (79). Kim et al (70) examined the surface of TFs with a scanning electron microscope before and after fatigue testing. The path of crack propagation appeared to be different for TF versus nonelectropolished (Helix and ProTaper) instruments. Crack propagation showed a tortuous, nonlinear path that was not related to the surface texture of the TF instruments. In contrast, ProTaper and Helix instruments showed conspicuous machining marks (grooves) along the faces of the flutes. The authors assumed that the direction of crack propaga- tion may contribute to a significantly higher resistance to cyclic fatigue in the TFs than in the nonelectropolished files.

The effect of steam sterilization on the fatigue life of conventional NiTi instruments has been examined, but no significant effects were discernible (80). Other studies showed that sterilization cycles in an autoclave also have no (adverse) effect on mechanical properties (81-83). The results suggest that any enthalpy generated during autoclave processing does not provide enough energy to enable a heat treatment effect that could cause a crystalline phase change similar to that of the new manufacturing techniques. It has been reported that a temperature of $170^{\circ} \mathrm{C}$ is required to initiate reorganization, $430^{\circ} \mathrm{C}-440^{\circ} \mathrm{C}$ to obtain maximum fatigue resistance, and $640^{\circ} \mathrm{C}$ for complete martensitic to austenitic conversion (32). Thus, little if any detrimental effect on the properties of the NiTi files should be anticipated after sterilization. Recently, Hilfer et al (84) found that autoclave sterilization conditions $\left(132^{\circ} \mathrm{C}\right.$ for 6 minutes) did not significantly affect the cyclic fatigue behavior of GTX (20/.04 and $20 / .06)$ or the TF (25/.04). However, a statistically significant decrease of cycles to failure after autoclaving was observed in TF size 25/.06.

Technological developments in metallurgy offer the possibility of enhancement of contemporary NiTi files, with one of the most promising processes being post-machining heat treatment. Recently, a special thermal process was introduced to NiTi files after the grinding process completed by SybronEndo. Theoretically, the main advantage is not only to improve the flexibility and strength with thermal treatment but also at the same time by modifying the crystalline structure of the alloy to accommodate some of the internal stress caused by the grinding process. Therefore, the new technique could eliminate many drawbacks of the grinding process and produce instruments with superior mechanical resistance. The manufacturer claims that K3XF provides clinicians with the basic features of the original $\mathrm{K} 3$ plus an extraordinary new level of flexibility and resistance to cyclic fatigue with the proprietary R-phase technology. Gambarini et al (85) investigated the cycle fatigue resistance of $\mathrm{K} 3$ and $\mathrm{K} 4$ prototypes (K3XF); only the latter were subjected to a proprietary thermal treatment after the grinding process. The study found that $K 4$ prototype instruments showed a significant increase in the mean number of cycles to failure when compared with $\mathrm{K} 3$ instruments (1198 \pm 279 vs $542 \pm 81)$. Furthermore, the effect of autoclave sterilization on the cyclic fatigue resistance of $\mathrm{K} 3 \mathrm{XF}$ was also evaluated by the same research group (86). The results showed that repeated cycles of autoclave sterilization do not seem to influence the cyclic fatigue resistance of K3, Mtwo, or Vortex NiTi instruments. However, autoclaving increased the fatigue resistance of $\mathrm{K} 3 \mathrm{XF}$ prototypes of rotary instruments.

\section{Torsional Properties}

The International Organization for Standardization/American National Standards Institute specifications have described a test method for (stainless steel) root canal reamers and files in which $3 \mathrm{~mm}$ of the tip of the instrument is rigidly fixed and subjected to twisting in a clockwise or a counterclockwise direction (87). This test method has been adopted for many studies on the mechanical properties of NiTi instruments $(88,89)$.

It has been shown that certain proprietary heat treatment sequences could enhance fatigue resistance of NiTi alloy (38-41, 66, 68-72). It is expected that thermomechanically treated NiTi instruments maintain the same torsional properties as conventional SE NiTi instruments. In the first study on this subject, Johnson et al (68) showed that the torque at the fracture of NiTi ProFile 25/.04 instruments made from M-Wire was similar to that of existing ProFile files made from SE wire. Kramkowski and Bahcall (90) also found that 
there was no statistical difference when comparing the torque $(\mathrm{g} / \mathrm{cm})$ required to induce a torsional failure of ProFile GT and ProFile GTX files of identical file sizes. However, the angle of deflection of ProFile GT was significantly greater before separation than that of ProFile GTX for all file sizes tested except for 20/.04. Recently, Gao et al (41) studied the torsional properties of SE wire files, M-Wire Files, and Vortex Blue NiTi files. Results showed that M-Wire held a slight edge over Vortex Blue NiTi in torsional strength. SE wire and Vortex Blue NiTi displayed the same average peak torque $(1 \mathrm{~N} / \mathrm{cm})$. Vortex Blue showed the greatest distortion angle at break, whereas SE wire and M-Wire showed no significant differences in the degree of rotation. It is assumed that the greater ductility measured by the angular distortion might give Vortex Blue a higher "safety factor" because files showing more detectable distortion of the cutting spirals are more likely to be discarded before breakage (91).

Peters et al (92) evaluated the torque of HyFlex instruments during canal preparation. HyFlex rotary instruments showed similar torsional resistance as instruments made from conventional NiTi. Torque during canal preparation was significantly higher for small instruments used in the single-length technique in which all instruments are used to the full working length in regular sequence (93), except for size 40.04 taper, compared with a crown-down approach. Interestingly, although no instrument fractured, $82 \%$ of them were plastically deformed, and $37 \%$ of those remained deformed after a sterilization cycle.

Park et al (94) compared the repetitive torsional resistance of TF and 4 other commercially available NiTi instruments. The TF presented the lowest torsional resistance in this study. The value was significantly lower than for RaCe (FKG Dentaire, La Chaux-de-fonds, Switzerland) with a relatively similar cross-sectional design. Despite the purported advantage of the twisting process and a smooth surface finish, all TF instruments fractured at the first (repeated) application of torque. One possible explanation may be related to the thermomechanical manufacturing process. An instrument made from the R-phase alloy would be more flexible, allowing a greater amount of deformation at a similar torque than austenitic NiTi. Furthermore, the shaft length of TF (23 mm, as opposed to 25-mm-long instruments for other groups) may have contributed, in part, to lower torsional resistance; the longer the distance between the shaft and clamped position (site of stress application), the more evenly the torsional stress would be distributed. In addition, when evaluating the torsional strength, distortion angle, and toughness of TF against 4 other NiTi files, the TF exhibited the lowest yield strength and ultimate strength (94).

The effects of multiple autoclave cycles on the torsional load behavior of the novel rotary NiTi file systems have also been evaluated $(95,96)$. Repeated steam autoclaving did not affect torsional resistance for unused ProFile Vortex (M-Wire), TF, and CM Wire files (95). ProFile Vortex and CM displayed significantly greater resistance to torsional load than TF. Angular deflection values for the TF and CM were significantly higher than for ProFile Vortex, with the TF showing greater rotational distortion than $\mathrm{CM}$. Therefore, based on laboratory results, CM Wire files may have the combined advantage of greater torsional strength and high deformation before failure compared with ProFile Vortex and TF. King et al (96) evaluated the effects of repeated autoclaving on the torsional strength of TFs and GTX files. Results showed that the mean torque at failure was significantly lower for GTX files after 3 and 7 autoclave cycles. Interestingly, the number of autoclave cycles did not significantly affect the torsional moment of the TF. A special conditioning treatment of the TF, a proprietary process called Deox that removes the oxidation layer and any surface impurities but does not remove any of the base material (79), finishes the surface of the file while respecting the integrity of the underlying grain structure. It is claimed that this process is not equivalent to the surface electropo- lishing finishing technique but is designed to improve torsional resistance, increase instrument strength, and reduce surface defects $(97,98)$. Gambarini et al (97) confirmed the value of this Deox treatment by reporting that TF with Deox treatment had $90 \%$ greater torque failure values than TF with no deoxidation treatment.

Increased rotational speed may lead to a higher cutting ability and could compensate for increased fatigue. Recommendations given in textbooks for the optimal speed of rotary files vary from instrument to instrument (16). Various reasons exist to maintain the speed SE NiTi instrument rotation low (eg, below $300 \mathrm{rpm}$ ) including a longer time to fatigue failure (56) and less incidence of taper lock (99). A recent article advocates higher speeds $(500 \mathrm{rpm})$ for Vortex instruments based on the assumption that the higher cutting efficiency would more than compensate for those disadvantages (38). The authors concluded that M-Wire, with its extended fatigue resistance, used to manufacture Vortex rotaries would be particularly suited to higher speeds. Bardsley et al (100) tested Vortex rotary files at 3 different settings (ie, 200, 400, and $600 \mathrm{rpm}$ ) in order to assess the influence of these speed settings on the torque and apical force inside artificial root canals. They found that rotational speed had a significant impact on preparation with Vortex rotaries, with instruments at $400 \mathrm{rpm}$ generating less torque and force than those at $200 \mathrm{rpm}$. An additional speed increase to $600 \mathrm{rpm}$ did not provide any further benefit.

\section{Thermomechanically Treated New NiTi Instruments}

The thermomechanically treated new NiTi instruments described later show several of the latest modifications.

\section{Profile GT Series X}

Preliminary evidence suggested that using M-Wire increased the fatigue lifespan of rotary instruments while maintaining the same torsional properties as traditional NiTi instruments (68). The first commercially available endodontic rotary system using the new MWire NiTi material was GTX in 2008. The design principles of the ProFile GT instrument are mostly still followed in the ProFile GTX. The main differences are the use of M-Wire for GTX, subtle changes in the longitudinal design, and a different approach to instrument usage, emphasizing the use of the no. 20/.06 rotary. The GTX set currently includes tip sizes 20, 30, and 40 in tapers ranging from .04 to .10. The recommended rotational speed for GT and GTX files is $300 \mathrm{rpm}$, and the instruments should be used with minimal apical force and a slight pecking action (http://www.scribd.com/doc/35935026/GT-Series-XBrochure).

\section{TFs}

The TF is made from R-phase wire and was introduced in 2008. The manufacturer claims that their proprietary twisting process with concurrent heat treatment and protection of the crystalline structure imparts superior flexibility and resistance to fatigue (66). The instrument was first available with only no. 25 tip sizes in tapers .04 up to .12. However, instruments with tip sizes no. 30, 35, and 40 were recently added. The recommended rotational speed is $500 \mathrm{rpm}$ (www.tfwithrphase.com/images/3987_TF_Brochure.pdf).

\section{Profile Vortex}

In 2009, Dentsply Tulsa Dental introduced ProFile Vortex, the next generation in its ProFile instrument series. Similar to GTX, Vortex files are also manufactured from M-Wire. The Vortex file has a triangular cross-section without radial lands. The manufacturer suggests that this geometry promotes a more efficient cutting behavior and decreased 

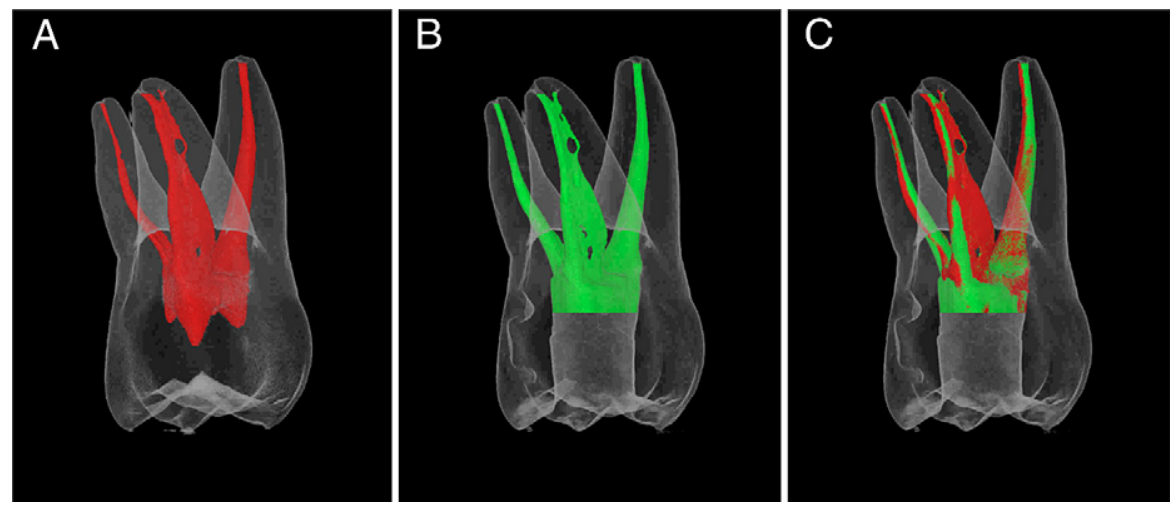

Figure 3. Microcomputed tomographic reconstructions of root canals treated with Typhoon CM NiTi instruments. $(A)$ The preoperative canal system is shown in $r e d,(B)$ the postoperative canal shape in green, and $(C)$ the superimposition.

"threading-in" effects. ProFile Vortex is available in ISO tip sizes from 15 to 50 and in .04 and .06 taper. The recommended rotational speed for ProFile Vortex is $500 \mathrm{rpm}$.

\section{HyFlex and Typhoon CM Instruments}

CM NiTi files are flexible (Fig. 3A-C), have high resistance to cyclic fatigue $(39,40)$, and have normal torsional strength (92). HyFlex instruments made from CM Wire were commercialized in 2011. They exhibit a lower percent in weight of nickel $(52 \mathrm{Ni} \% \mathrm{wt})$ than the common 54.5-57 Ni \%wt of the great majority of commercially available SE NiTi rotary instruments (101). The recommended rotational speed is $500 \mathrm{rpm}$ with a torque setting of up to $2.5 \mathrm{~N} / \mathrm{cm}$ (www. hyflexcm.com/DevDownloads/30464A_HYFLEX-CM_bro.pdf).

TYPHOON Infinite Flex NiTi (TYF CM) files are also made from CM Wire and were introduced in 2011. The recommended rotational speed is $400 \mathrm{rpm}$ with a torque setting up to $2-2.75 \mathrm{~N} / \mathrm{cm}$ (www. clinicalresearchdental.com/products.php?product=Typhoon-InfiniteFlex-NiTi-Files*).

\section{K3XF}

The design of $\mathrm{K} 3$ instruments was updated by SybronEndo, and the system has been available under the name of K3XF since 2011 . The manufacturer claims that $\mathrm{K} 3 \mathrm{XF}$ has a third radial land and variable pitch, superior flexibility, and resistance to fatigue. The recommended rotational speed is $350-500 \mathrm{rpm}$ with a torque setting of up to $3 \mathrm{~N} / \mathrm{cm}$ (http://www.sybronendo.com/cms-filesystem-action?file=/ sybronendo-pdf/k3xf-sell-sheet.pdf).

\section{Vortex Blue}

Surface engineering techniques have been shown to improve the surface hardness and wear resistance of NiTi instruments (102-105). Vortex Blue, a newly developed NiTi rotary instrument made from M-Wire, has been designed to meet these new challenges with improved fatigue resistance, cutting efficiency, flexibility, and canal centering capability. Vortex Blue instruments show a unique "blue color" compared with traditional SE NiTi instruments. The "blue-color" oxide surface layer of Vortex Blue files is a result of the proprietary manufacturing process. The relatively hard titanium oxide surface layer on the Vortex Blue instrument may compensate for the loss of hardness compared with ProFile Vortex M-Wire (41) while improving the cutting efficiency and wear resistance. The recommended rotational speed is $500 \mathrm{rpm}$ with a torque setting of between 0.75 and $3.68 \mathrm{~N} / \mathrm{cm}$ (http://store.maillefer.com/lit2/pdfs/BRVB_6-11B_ VortexBlue_Broch.pdf).

\section{Clinical Applications}

Flexibility is regarded as one of the most important mechanical properties of rotary NiTi instruments, and the choice of one instrument over another often hinges on this $(16,106)(\mathrm{Fig} .4 A-C)$. Along with the progress of raw materials, endodontic files have shown a trend of continuous improvement in flexibility and fracture resistance. The new endodontic NiTi instruments manufactured with thermomechanical treatment of NiTi wires have greater flexibility than similar instruments made from conventional SE wires $(41,43,107)$. To maximize their clinical potential, clinicians should expect to make corresponding adjustments during the transition either from stainless steel hand files
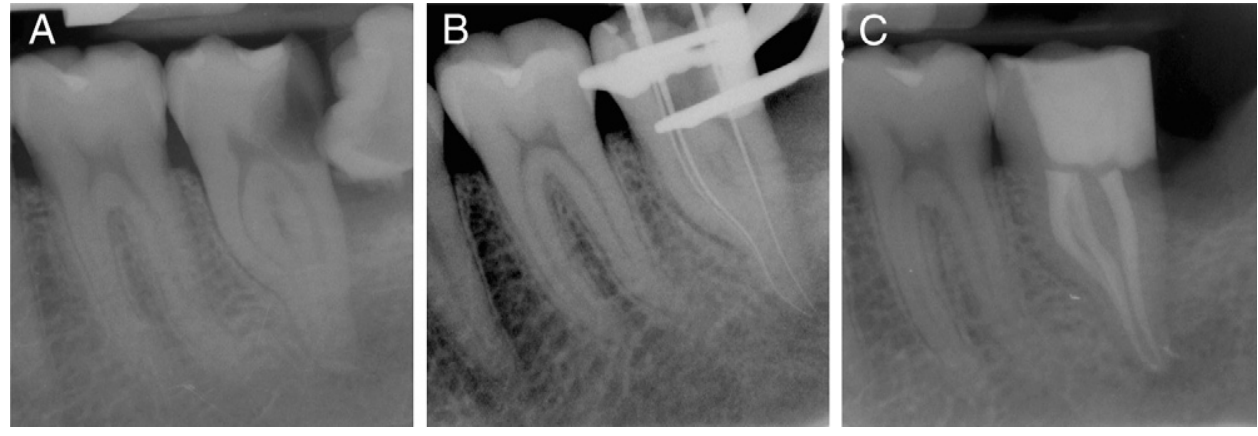

Figure 4. Double-curved mesial canals of lower second molar instrumented by HyFlex NiTi files. $(A)$ A preoperative radiograph, $(B)$ the working length radiograph, and $(C)$ obturation. (Courtesy of Visual Endodontics 2012, Dr Mark Parhar.) 


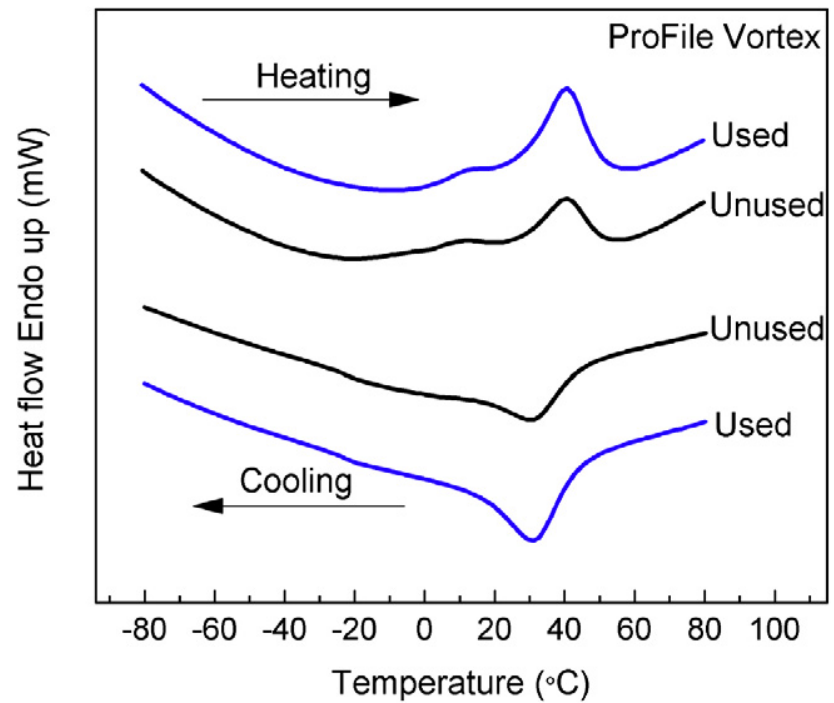

Figure 5. DSC curves for test specimens obtained from unused and clinically used ProFile Vortex instruments.

to rotary NiTi system or between rotary file systems featuring different NiTi materials. For example, because of the improved flexibility of thermomechanically treated NiTi files, the dentist may need to apply less pressure against the canal wall than with conventional SE NiTi files of the same size and taper.

As a general rule, flexible instruments have been assumed to be less resistant to torsional load but are resistant to cyclic fatigue. Thus, various NiTi rotary systems should be used as required by the specific characteristics of each root canal in the clinical situation $(16,108)$. NiTi files with high flexibility and good cyclic fatigue resistance could be used for preparing curved canals. Vortex Blue and CM Wire files may have the combined advantage of greater torsional strength and high deformation before failure. Originally, the manufacturer of HyFlex recommended a single-length technique (93) combined with a coronal flare. Interestingly, they have recently added a crown-down sequence to their recommendation (109).

The development of visible alterations in flute pitch and helical angle during instrumentation procedures is beneficial in alerting practitioners to discard files before fracture (110). The ProFile Vortex file appears less likely to produce such deformations, and separation might occur without warning. Manufacturer instructions affirm that ProFile Vortex instruments are intended exclusively for single-patient use. Such instructions seem reasonable, given the low deformational properties of this file. Recently, 1 study (111) evaluated the incidence and type of ProFile Vortex instrument defects during a predefined schedule of clinical use by the undergraduate students in a dental school. Results showed that none of the 2203 Vortex files showed any unwinding after clinically use except for 1 file, which fractured. The reason for the fracturing as revealed by fractographic analysis was shear stress. Clinical single-use had no evident effect upon phase transformation for Vortex files (111). Unused and clinically used files are a mixture of austenite and martensite structure at body temperature (Fig. 5).

\section{Conclusion}

The mechanical properties of the NiTi alloy can be improved by altering the microstructure via cold work and heat treatment. Therefore, new NiTi endodontic files with superior properties can be developed through special thermomechanical processing, which is a metallurgical process that integrates hardening and heat treatment into a single process. The newly developed thermomechanical treatment of NiTi files gives them better flexural fatigue resistance than files of similar design and size made from conventional NiTi alloy. The unique material properties make them particularly suited for endodontic treatment. Although the details of the thermomechanical treatment history of the new NiTi wires remain unknown, it seems that thermomechanical processing is a very promising method of gaining substantial benefits with regards to the efficiency and safety of contemporary endodontic instruments.

\section{Acknowledgments}

The authors deny any conflicts of interest related to this study.

\section{References}

1. Eggert C, Peters 0, Barbakow F. Wear of nickel-titanium lightspeed instruments evaluated by scanning electron microscopy. J Endod 1999;25:494-7.

2. Sattapan B, Nervo GJ, Palamara JE, et al. Defects in rotary nickel-titanium files after clinical use. J Endod 2000;26:161-5.

3. Arens FC, Hoen MM, Steiman HR, et al. Evaluation of single-use rotary nickel-titanium instruments. J Endod 2003;29:664-6.

4. Peters OA. Current challenges and concepts in the preparation of root canal systems: a review. J Endod 2004;35:559-67.

5. Parashos P, Gordon I, Messer HH. Factors influencing defects of rotary nickeltitanium endodontic instruments after clinical use. J Endod 2004;30:722-5.

6. Parashos P, Messer HH. Questionnaire survey on the use of rotary nickel-titanium endodontic instruments by Australian dentists. Int Endod J 2004;37:249-59.

7. Spili P, Parashos P, Messer HH. The impact of instrument fracture on outcome of endodontic treatment. J Endod 2005;31:845-50.

8. Knowles KI, Hammond NB, Biggs SG, et al. Incidence of instrument separation using LightSpeed rotary instruments. J Endod 2006;32:14-6.

9. Parashos $\mathrm{P}$, Messer HH. Rotary NiTi instrument fracture and its consequences. J Endod 2006;32:1031-43.

10. Tzanetakis GN, Kontakiotis EG, Maurikou DV, et al. Prevalence and management of instrument fracture in the postgraduate endodontic program at the Dental School of Athens: a five-year retrospective clinical study. J Endod 2008;34:675-8.

11. Shen Y, Cheung GS, Bian Z, et al. Comparison of defects in ProFile and ProTaper systems after clinical use. J Endod 2006;32:61-5.

12. Wei $\mathrm{X}$, Ling $\mathrm{J}$, Jiang $\mathrm{J}$, et al. Modes of failure of ProTaper nickel-titanium rotary instruments after clinical use. J Endod 2007;33:276-9.

13. Cheung GSP. Instrument fracture: mechanisms, removal of fragments, and clinical outcomes. Endod Topics 2007;16:1-26.

14. Shen Y, Cheung GS, Peng B, et al. Defects in nickel-titanium instruments after clinical use. Part 2: fractographic analysis of fractured surface in a cohort study. J Endod 2009;35:133-6.

15. Plotino G, Grande NM, Cordaro M, et al. A review of cyclic fatigue testing of nickeltitanium rotary instruments. J Endod 2009;35:1469-76.

16. Peters OA, Peters CI. Cleaning and shaping of the root canal system. In: Hargeaves KM, Cohen S, eds. Pathways of the Pulp, 10th ed. St Louis, MO: Mosby Elsevier; 2011:288-348

17. Liu Y, McCormick PG. Thermodynamic analysis of the martensitic transformation in NiTi-II: effect of transformation cycling. Acta Mater 1994;7:2407-13.

18. Frick C, Ortega A, Tyber J, et al. Thermal processing of polycrystalline NiTi shape memory alloys. Mater Sci Eng A 2005;405:34-49.

19. Gutmann JL, Gao Y. Alteration in the inherent metallic and surface properties of nickel-titanium root canal instruments to enhance performance, durability and safety: a focused review. Int Endod J 2012;45:113-28.

20. Walia H, Brantley WA, Gerstein H. An initial investigation of the bending and torsional properties of nitinol root canal files. J Endod 1988;14:346-51.

21. Brantley WA. Orthodontic wires. In: Brantley WA, Eliades T, eds. Orthodontic Materials: Scientific and Clinical Aspects, 52-6. Stuttgart: Thieme; 2001:77-103.

22. Yoneyama T, Kobavashi C. Endodontic instruments for root canal treatment using Ti-Ni shape memory alloys. In: Yoneyama T, Miyazaki S, eds. Shape Memory Alloys for BiomedicalApplications. Cambridge: Woodhead Publishing Limited; 2009:297-305.

23. Buehler WJ, Wang FE. A summary of recent research on the Nitinol alloys and their potential application in ocean engineering. Ocean Eng 1967;1:105-20.

24. Thompson SA. An overview of nickel-titanium alloys used in dentistry. Int Endod J 2000;33:297-310.

25. Otsuka K, Wayman CM. Shape Memory Materials, 1st ed. Cambridge, UK: Cambridge University Press; 1998.

26. Brantley WA, Svec TA, Iijima M, et al. Differential scanning calorimetric studies of nickel-titanium rotary endodontic instruments. J Endod 2002;28:567-72. 
27. Kuhn G, Tavernier B, Jordan L. Influence of structure on nickel-titanium endodontic instrument failure. J Endod 2001;27:516-20.

28. Kuhn G, Jordan L. Fatigue and mechanical properties of nickel titanium endodontic instruments. J Endod 2002;28:716-20.

29. Hayashi Y, Yoneyama T, Yahata Y, et al. Phase transformation behaviour and bending properties of hybrid nickel-titanium rotary endodontic instruments. Int Endod J 2007;40:247-53.

30. Yahata Y, Yoneyama T, Hayashi Y, et al. Effect of heat treatment on transformation temperatures and bending properties of nickel-titanium endodontic instruments. Int Endod J 2009;42:621-6.

31. Alapati SB, Brantley WA, Iijima M, et al. Micro-XRD and temperature-modulated DSC investigation of nickel-titanium rotary endodontic instruments. Dent Mater 2009;25:1221-9.

32. Zinelis S, Darabara M, Takase T, et al. The effect of thermal treatment on the resistance of nickel-titanium rotary files in cyclic fatigue. Oral Surg Oral Med Oral Pathol Oral Radiol Endod 2007;103:843-7.

33. CM Wire press release. Johnson City, TN: DS Dental; 2010.

34. Davis JR. ASM Specialty Handbook: Nickel, Cobalt, and Their Alloys. Materials Park, OH: ASM International; 2000.

35. Hull D. Fractography: Observing, Measuring and Interpreting Fracture Surface Topography. Cambridge, UK: Cambridge University Press; 1999.

36. Cheung GS, Shen Y, Darvell BW. Does electropolishing improve the low-cycle fatigue behavior of a nickel-titanium rotary instrument in hypochlorite? J Endod 2007:33:1217-21.

37. Condorelli GG, Bonaccorso A, Smecca E, et al. Improvement of the fatigue resistance of NiTi endodontic files by surface and bulk modifications. Int Endod J 2010; 43:866-73.

38. Gao Y, Shotton V, Wilkinson $\mathrm{K}$, et al. Effects of raw material and rotational speed on the cyclic fatigue of ProFile Vortex rotary instruments. J Endod 2010;36:1205-9.

39. Shen $\mathrm{Y}$, Qian $\mathrm{W}$, Abtin $\mathrm{H}$, et al. Fatigue testing of controlled memory wire nickeltitanium rotary instruments. J Endod 2011;37:997-1001.

40. Shen Y, Qian W, Abtin H, et al. Effect of environment on fatigue failure of controlled memory wire nickel-titanium rotary instruments. J Endod 2012;38: 376-80.

41. Gao Y, Gutmann JL, Wilkinson K, et al. Evaluation of the impact of raw materials on the fatigue and mechanical properties of ProFile Vortex rotary instruments. J Endod 2012;38:398-401.

42. Zhou H, Shen Y, Zheng W, et al. The mechanical properties of controlled memory and superelastic NiTi wires used in the manufacture of rotary endodontic instruments. J Endod 2012;38:1535-40.

43. Hou XM, Yahata Y, Hayashi Y, et al. Phase transformation behaviour and bending property of twisted nickel-titanium endodontic instruments. Int Endod J 2011;44: $253-8$.

44. Shen Y, Zhou HM, Zheng YF, et al. Metallurgical characterization of controlled memory wire nickel-titanium rotary instruments. J Endod 2011; 37:1566-71.

45. Ye J, Gao Y. Metallurgical characterization of M-wire nickel-titanium shape memory alloy used for endodontic rotary instruments during low-cycle fatigue. J Endod 2012;38:105-7.

46. Brantley WA, Svec TA, Iijima M, et al. Differential scanning calorimetric studies of nickel-titanium rotary endodontic instruments after simulated clinical use. J Endod 2002;28:774-8.

47. Alapati SB, Brantley WA, Iijima M, et al. Metallurgical characterization of a new nickel-titanium wire for rotary endodontic instruments. J Endod 2009;35: 1589-93.

48. Gambarini G, Gerosa R, De Luca M, et al. Mechanical properties of a new and improved nickel-titanium alloy for endodontic use: an evaluation of file flexibility. Oral Surg Oral Med Oral Pathol Oral Radiol Endod 2008;105:798-800.

49. Pruett JP, Clement DJ, Carnes DL Jr. Cyclic fatigue testing of nickel-titanium endodontic instruments. J Endod 1997;23:77-85.

50. Cheung GS, Peng B, Bian Z, et al. Defects in ProTaper $\$ 1$ instruments after clinical use: fractographic examination. Int Endod J 2005;38:802-9.

51. Spanaki-Voreadi AP, Kerezoudis NP, Zinelis S. Failure mechanism of ProTaper NiTi rotary instruments during clinical use: fractographic analysis. Int Endod J 2006; 39:171-8.

52. Cheung GS, Darvell BW. Fatigue testing of a NiTi rotary instrument. Part 2: Fractographic analysis. Int Endod J 2007;40:619-25.

53. McKelvey AL, Ritchie RO. Fatigue-crack growth behavior in the superelastic and shape-memory material nitinol. Metall Mater Trans A 2001;32A:731-43.

54. Haikel Y, Serfaty R, Bateman G, et al. Dynamic and cyclic fatigue of engine-driven rotary nickel-titanium endodontic instruments. J Endod 1999;25:434-40.

55. Hubscher W, Barbakow F, Peters OA. Root canal preparation with FlexMaster: assessment of torque and force in relation to canal anatomy. Int Endod J 2003; 36:883-90.
56. Ullmann CJ, Peters OA. Effect of cyclic fatigue on static fracture loads in ProTaper nickel-titanium rotary instruments. J Endod 2005;31:183-6.

57. Plotino G, Grande NM, Sorci E, et al. A comparison of cyclic fatigue between used and new Mtwo Ni-Ti rotary instruments. Int Endod J 2006;39:716-23.

58. Grande NM, Plotino G, Pecci R, et al. Cyclic fatigue resistance and threedimensional analysis of instruments from two nickel-titanium rotary systems. Int Endod J 2006;39:755-63.

59. Peters OA, Roehlike JO, Baumann MA. Effect of immersion in sodium hypochlorite on torque and fatigue resistance of nickel-titanium instruments. J Endod 2007;33: $589-93$.

60. Plotino G, Grande NM, Sorci E, et al. Influence of a brushing working motion on the fatigue life of NiTi rotary instruments. Int Endod J 2007;40:45-51.

61. Li UM, Lee BS, Shih CT, et al. Cyclic fatigue of endodontic nickel-titanium rotary instruments: static and dynamic tests. J Endod 2002;28:448-51.

62. Low D, Ho AW, Cheung GS, et al. Mathematical modeling of flexural behavior of rotary nickel-titanium endodontic instruments. J Endod 2006;32:545-8.

63. Cheung GS, Darvell BW. Fatigue testing of a NiTi rotary instrument. Part 1: strainlife relationship. Int Endod J 2007;40:612-8.

64. Cheung GS, Shen Y, Darvell BW. Effect of environment on low-cycle fatigue of a nickel-titanium instrument. J Endod 2007;33:1433-7.

65. Berendt $\mathrm{CJ}$, Yang J. Endodontic instruments with improved fatigue resistance. In: Berg B, Mitchell MR, Proft J, eds. International Conference on Shape Memory and Superelastic Technologies. Pacific Grove, CA: ASM International; 2006.

66. Gambarini G, Grande NM, Plotino G, et al. Fatigue resistance of engine-driven rotary nickel-titanium instruments produced by new manufacturing methods. J Endod 2008;34:1003-5.

67. Al-Hadlaq SM, Aljarbou FA, AlThumairy RI. Evaluation of cyclic flexural fatigue of M-wire nickel-titanium rotary instruments. J Endod 2010;36:305-7.

68. Johnson E, Lloyd A, Kuttler S, et al. Comparison between a novel nickel-titanium alloy and 508 nitinol on the cyclic fatigue life of ProFile 25/.04 rotary instruments. J Endod 2008;34:1406-9.

69. Larsen CM, Watanabe I, Glickman GN, et al. Cyclic fatigue analysis of a new generation of nickel-titanium rotary instruments. J Endod 2009;35:401-3.

70. Kim HC, Yum J, Hur B, et al. Cyclic fatigue and fracture characteristics of ground and twisted nickel-titanium rotary files. J Endod 2010;36:147-52.

71. Bhagabati N, Yadav S, Talwar S. An in vitro cyclic fatigue analysis of different endodontic nickel-titanium rotary instruments. J Endod 2012;38:515-8.

72. Rodrigues RC, Lopes HP, Elias $\mathrm{CN}$, et al. Influence of different manufacturing methods on the cyclic fatigue of rotary nickel-titanium endodontic instruments. J Endod 2011;37:1553-7.

73. Pedullà E, Grande NM, Plotino G, et al. Cyclic fatigue resistance of three different nickel-titanium instruments after immersion in sodium hypochlorite. J Endod 2011;37:1139-42.

74. Liaw YC, Su YY, Lai YL, et al. Stiffness and frictional resistance of a superelastic nickel-titanium orthodontic wire with low-stress hysteresis. Am J Orthod Dentofacial Orthop 2007;131:578.e12-8

75. Tripi TR, Bonaccorso A, Condorelli GG. Cyclic fatigue of different nickel-titanium endodontic rotary instruments. Oral Surg Oral Med Oral Pathol Oral Radiol Endod 2006;102:e106-14.

76. Miao W, Mi X, Zhu M, et al. Effect of surface preparation on mechanical properties of a NiTi alloy. Mater Sci Forum 2002;394-395:173-6.

77. Rapisarda E, Bonaccorso A, Tripi TR, et al. The effect of surface treatments of nickel-titanium files on wear and cutting efficiency. Oral Surg Oral Med Oral Pathol Oral Radiol Endod 2000;89:363-8.

78. Herold KS, Johnson BR, Wenckus CS. A scanning electron microscopy evaluation of microfractures, deformation and separation in EndoSequence and Profile nickel-titanium rotary files using an extracted molar tooth model. J Endod 2007;33:712-4

79. Sabala G. Letter to the editor. J Endod 2010;36:951

80. Mize SB, Clement DJ, Pruett JP, et al. Effect of sterilization on cyclic fatigue of rotary nickel-titanium endodontic instruments. J Endod 1998;24:843-7.

81. Silvaggio J, Hicks ML. Effect of heat sterilization on the torsional properties of rotary nickel-titanium endodontic files. J Endod 1997;23:731-4.

82. Yared GM, Bou Dagher FE, Machtou P. Cyclic fatigue of ProFile rotary instruments after clinical use. Int Endod J 2000;33:204-7.

83. Viana AC, Gonzalez BM, Buono VT, et al. Influence of sterilization on mechanical properties and fatigue resistance of nickel-titanium rotary endodontic instruments. Int Endod J 2006;39:709-15.

84. Hilfer PB, Bergeron BE, Mayerchak MJ, et al. Multiple autoclave cycle effects on cyclic fatigue of nickel-titanium rotary files produced by new manufacturing methods. J Endod 2011;37:72-4

85. Gambarini G, Plotino G, Grande NM, et al. Mechanical properties of nickeltitanium rotary instruments produced with a new manufacturing technique. Int Endod J 2011;44:337-41. 
86. Plotino G, Costanzo A, Grande NM, et al. Experimental evaluation on the influence of autoclave sterilization on the cyclic fatigue of new nickel-titanium rotary instruments. J Endod 2012;38:222-5.

87. International Organization for Standardization. Dentistry-Root-canal Instruments-Part 1: General requirements and test methods. ISO 36303631, 2008.

88. Melo MC, Pereira ES, Viana AC, et al. Dimensional characterization and mechanical behaviour of K3 rotary instruments. Int Endod J 2008;41:329-38.

89. Barbosa FO, Gomes JA, de Araújo MC. Influence of electrochemical polishing on the mechanical properties of $\mathrm{K} 3$ nickel-titanium rotary instruments. J Endod 2008; 34:1533-6.

90. Kramkowski TR, Bahcall J. An in vitro comparison of torsional stress and cyclic fatigue resistance of ProFile GT and ProFile GT Series X rotary nickel-titanium files. J Endod 2009;35:404-7.

91. Seto BG, Nicholls JI, Harrington GW. Torsional properties of twisted and machined endodontic files. J Endod 1990;16:355-60.

92. Peters OA, Gluskin AK, Weiss RA, et al. An in vitro assessment of the physical properties of novel Hyflex nickel-titanium rotary instruments. Int Endod J 2012;45:1027-34.

93. ColteneEndo. File sequence step by step card. Available at: http://hyflex.com/ DevDownloads/StepByStep_Extended.pdf. Accessed February 2, 2012.

94. Park SY, Cheung GS, Yum J, et al. Dynamic torsional resistance of nickel-titanium rotary instruments. J Endod 2010;36:1200-4.

95. Casper RB, Roberts HW, Roberts MD, et al. Comparison of autoclaving effects on torsional deformation and fracture resistance of three innovative endodontic file systems. J Endod 2011;37:1572-5.

96. King JB, Roberts HW, Bergeron BE, et al. The effect of autoclaving on torsional moment of two nickel-titanium endodontic files. Int Endod J 2012;45:156-61.

97. Gambarini G, Testarelli L, Galli M, et al. The effect of a new finishing process on the torsional resistance of twisted nickel-titanium rotary instruments. Minerva Stomatol 2010;59:401-6.

98. Gambarini G, Pompa G, De Carlo S, et al. An initial investigation on torsional properties of nickel-titanium instruments produced with a new manufacturing method. Aust Endod J 2009;35:70-2.
99. Yared GM, Bou Dagher FE, Machtou P. Influence of rotational speed, torque and operator's proficiency on ProFile failures. Int Endod J 2001;34:47-53.

100. Bardsley S, Peters CI, Peters OA. The effect of three rotational speed settings on torque and apical force with vortex rotary instruments in vitro. J Endod 2011; 37:860-4.

101. Zinelis S, Eliades T, Eliades G. A metallurgical characterization of ten endodontic $\mathrm{Ni}$-Ti instruments: assessing the clinical relevance of shape memory and superelastic properties of Ni-Ti endodontic instruments. Int Endod J 2010;43:125-34.

102. Schafer E. Effect of sterilization on the cutting efficiency of PVD-coated nickel-titanium endodontic instruments. Int Endod J 2002;35:867-72.

103. Tripi TR, Bonaccorso A, Rapisarda E, et al. Depositions of nitrogen on NiTi instruments. J Endod 2002;28:497-500.

104. Li UM, Iijima M, Endo K, et al. Application of plasma immersion ion implantation for surface modification of nickel-titanium rotary instruments. Dent Mater J 2007; 26:467-73.

105. Wolle CF, Vasconcellos MA, Hinrichs R, et al. The effect of argon and nitrogen ion implantation on nickel-titanium rotary instruments. J Endod 2009;35: 1558-62.

106. Paqué F, Ganahl D, Peters OA. Effects of root canal preparation on apical geometry assessed by micro-computed tomography. J Endod 2009;35:1056-9.

107. Testarelli L, Plotino G, Al-Sudani D, et al. Bending properties of a new nickeltitanium alloy with a lower percent by weight of nickel. J Endod 2011;37: 1293-5.

108. Walsch H. The hybrid concept of nickel-titanium rotary instrumentation. Dent Clin North Am 2004;48:183-202.

109. ColteneEndo. Crown-down technique step by step card. Available at: http:// hyflex.com/DevDownloads/Step-ByStep_CrownDown.pdf. Accessed February 2, 2012.

110. Peng B, Shen Y, Cheung GS, et al. Defects in ProTaper S1 instruments after clinical use: longitudinal examination. Int Endod J 2005;38:550-7.

111. Shen Y, Coil J, Zhou H, et al. ProFile Vortex instruments after clinical use: metallurgical properties study. J Endod 2012;38:1613-7. 